\title{
Tetraethylene glycol promoted two-step, one-pot rapid synthesis of indole-3-[1-11C]acetic Acid
}

Sojeong Leea, b, David L. Alexoffa, Colleen Shea ${ }^{a}$, Dohyun Kimª, Michael Schuellera, Joanna S. Fowlera,

$$
\text { Wenchao } \mathrm{Qu}^{\mathrm{a}, *}
$$

aBiological, Environmental \& Climate Sciences Department, Brookhaven National Laboratory,

$$
\text { Upton, NY 11973, USA }
$$

bDepartment of Chemistry, Stony Brook University, Stony Brook, NY 11794, USA

Email: wqu@bnl.gov

\section{Previously reported $\left[{ }^{11} \mathrm{C}\right] \mathrm{IAA}$ production method}

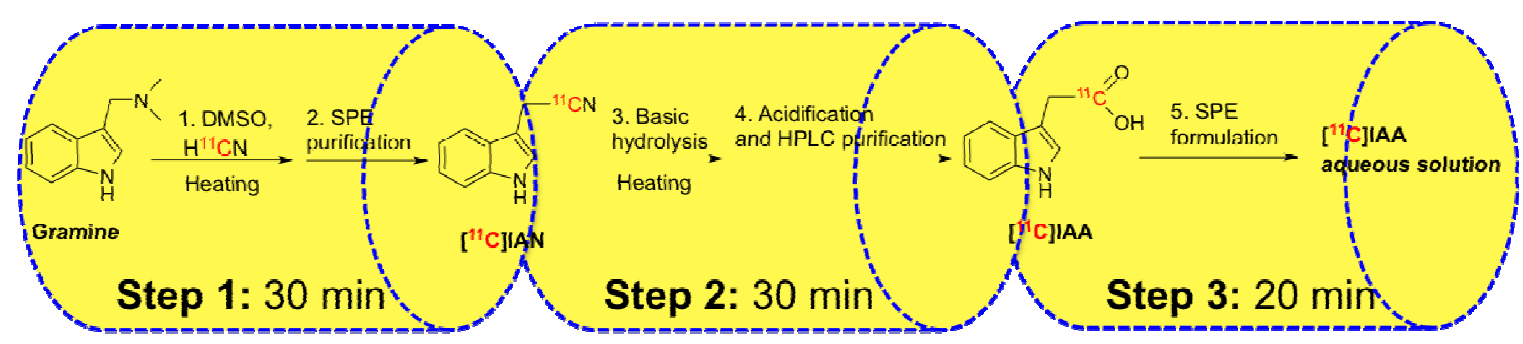

\section{New two-step, one-pot method}

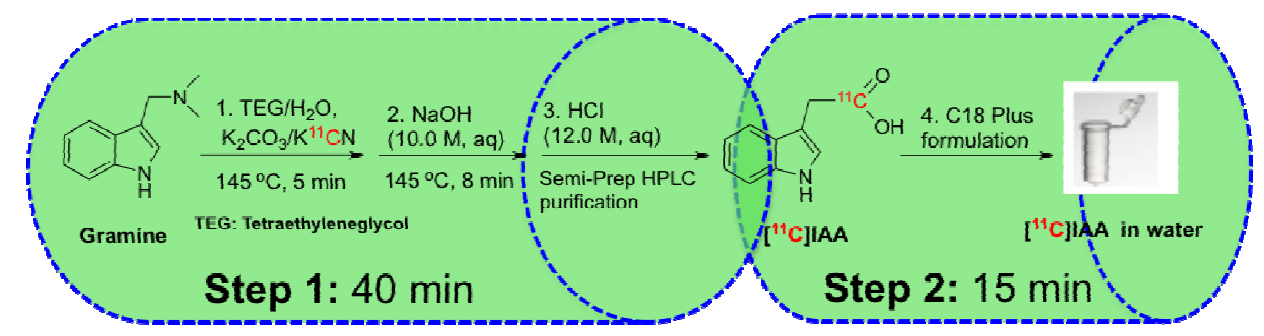

Table of contents graphic 


\begin{abstract}
An operationally friendly, two-step, one-pot process has been developed for the rapid synthesis of carbon-11 labeled indole-3-acetic acid ([11C]IAA or [11C]auxin). By replacing an aprotic polar solvent with tetraethylene glycol, nucleophilic $\left[{ }^{11} \mathrm{C}\right]$ cyanation and alkaline hydrolysis reactions were performed consecutively in a single pot without a time-consuming intermediate purification step. The entire production time for this updated procedure is $55 \mathrm{~min}$, which dramatically simplifies the entire synthesis and reduces the starting radioactivity required for a whole plant imaging study.
\end{abstract}

Keywords: Carbon-11 labeled indole-3-acetic acid, nucleophilic [11C]cyanation, tetraethylene glycol, two-step one-pot 


\section{Introduction}

Auxins are important plant hormones that play an essential role in plant cell growth and are involved in a wide variety of developmental processes, including initiation of leaf primordia, apical dominance, phototropism, fruit development, and lateral root production. ${ }^{1}$ Indole-3-acetic acid (IAA) is the most common and potent among naturally occurring auxins. ${ }^{2}$ Although IAA was structurally characterized in the 1930s, its translocation in the whole plant in response to growth and environmental stimuli is still not completely understood. ${ }^{3}$

Positron emission tomography (PET) has been used as an efficient tool to monitor the translocation of plant signaling molecules and carbon and nitrogen resource distribution in real time via in vivo imaging of whole plants. ${ }^{4-8}$ The use of PET to study plant metabolism has stimulated the development of rapid synthetic procedures for the radiosynthesis of PET radioisotope (e.g. carbon-11: $\mathrm{t}_{1 / 2}=20.4 \mathrm{~min}$, nitrogen-13: $\mathrm{t}_{1 / 2}=10 \mathrm{~min}$.) labeled small organic radiotracers designed to study plant metabolism and signaling pathways. ${ }^{9-11}$

Most radiotracers for plants, with the exception of the radioactive gases (e.g. ${ }^{11} \mathrm{CO}_{2},{ }^{13} \mathrm{NH}_{3}$, ${ }^{13} \mathrm{~N}_{2}$ ), require formulation in appropriate vehicles and volumes for administration to roots and leaves. We previously reported the radiosynthesis of Indole-3-[11C]acetic acid ([11C]IAA) and its biosynthetic precursor, $\left.{ }^{111} \mathrm{C}\right]$ indole-3-acetonitrile $\left(\left[{ }^{11} \mathrm{C}\right] \mathrm{IAN}\right)$ as well as indole-3-[11C]acetamide ([11C]IAM) as tools to examine signaling pathways for plant development. ${ }^{11}$ In the past year, we further polished the original synthesis method and also developed a reliable and remotely controllable formulation method to support our routine production of $\left.{ }^{11} \mathrm{C}\right] \mathrm{IAA}$ which is concentrated enough for in vivo plant imaging purposes $\left(0.2-0.4 \mathrm{GBq} / 0.15-0.3 \mathrm{~mL}\right.$, Scheme 1). ${ }^{12}$ However, the total production time with this method ranges from $80-85$ min, which is four halflives of carbon-11. In order to compensate for the radioactive decay due to the long radiosynthesis and formulation times and assure enough radioactivity for a plant imaging study, previous production generally required a $15-25 \mathrm{GBq}$ of starting $\mathrm{H}^{11} \mathrm{CN}$ radioactivity. The large amount of starting radioactivity and considerable handling during formulation resulted in unacceptably high 
radiation exposure to chemistry personnel.

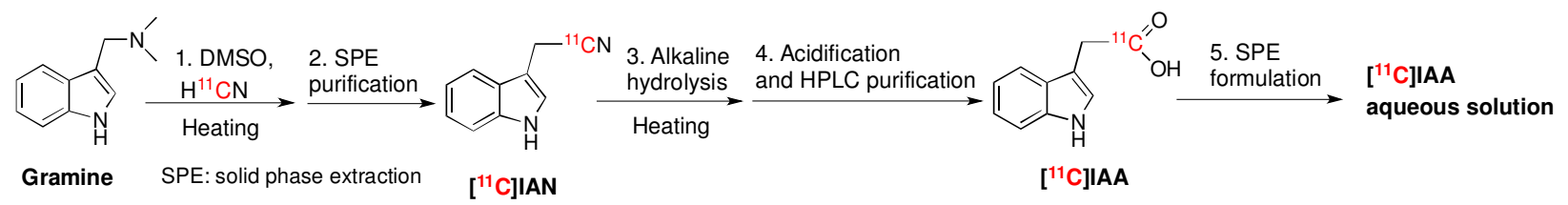

Scheme 1. Previously reported radiosynthesis process of $\left[{ }^{11} \mathrm{C}\right] \mathrm{IAA}^{12}$

With the aim of developing an efficient radiosynthesis method, i.e. the total process time at $60 \mathrm{~min}$ or less (rule-of thumb of carbon-11 labeled radiotracer production: overall time $<3$ half-lives), as well as reducing radiation exposure to the production radiochemists, we, herein, report our recent research improving the radiosynthesis of [11C]IAA: a simplified two-step, one-pot method with a significant reduction of total process time and amount of starting radioactivity.

\section{Results and discussion}

When considering the whole synthetic process of [11C]IAA (Scheme 1), we first focused on eliminating the step of solid phase extraction (SPE) purification of intermediate [ $\left.{ }^{11} \mathrm{C}\right] \mathrm{IAN}$. In our previous report, ${ }^{11,12}$ dimethyl sulfoxide was used in nucleophilic $\left[{ }^{11} \mathrm{C}\right]$ cyanation for synthesizing [11C]IAN from gramine and $\mathrm{H}^{11} \mathrm{CN}$. Except for the residual amount of ammonia $\left(\mathrm{NH}_{3}\right)$ from production of $\mathrm{H}^{11} \mathrm{CN}$, there was no other base involved in the nucleophilic $\left[{ }^{11} \mathrm{C}\right]$ cyanation. Although DMSO provided a very good yield for ${ }^{11} \mathrm{CN}^{-}$substitution, it inhibited the alkaline hydrolysis of $\left.{ }^{11} \mathrm{C}\right] \mathrm{IAN}$ and required removal by an SPE step. ${ }^{11}$ In order to switch to another solvent system, which could be compatible with both efficient nucleophilic $\left[{ }^{11} \mathrm{C}\right]$ cyanation and alkaline hydrolysis reactions, we resorted to the conditions reported by Snyder and Pilgrim over six decades ago. ${ }^{13}$ In their synthesis of IAA, gramine and $\mathrm{NaCN}$ were reacted in boiling aqueous ethanol solution for over eight hours to give IAN and IAM with $\sim 90 \%$ overall yield.

Inspired by this original process, we designed a two-step, one-pot method for the radiosynthesis of $\left[{ }^{11} \mathrm{C}\right] \mathrm{IAA}$ (Scheme 2). In the initial test of the one-pot IAA synthesis, gramine, $\mathrm{K}_{2} \mathrm{CO}_{3}$ and $\mathrm{KCN}$ were added into aqueous ethanol solution and the reaction mixture was boiled for 
10 min; after which concentrated base $\mathrm{NaOH}$ was immediately added into this mixture and maintained at boiling status for an additional $10 \mathrm{~min}$. The results from the analysis of the reaction mixture by analytical HPLC proved that a trace amount of IAA was formed. Encouraged by these results, we immediately conducted the $\left[{ }^{11} \mathrm{C}\right]$ cyanation reaction under similar conditions. Analysis by radio-HPLC showed an $8 \%$ yield of $\left[{ }^{11} \mathrm{C}\right] \mathrm{IAN}$ from the $\left[{ }^{11} \mathrm{C}\right]$ cyanation reaction. In addition, the detection of a trace amount of [11C]IAA also proved the feasibility of the radiosynthesis of [11C]IAA without the purification of the intermediate [11C]IAN (Table 1, Entry 1). We then carried out a series of radiosynthesis experiments utilizing this two-step, one-pot strategy.

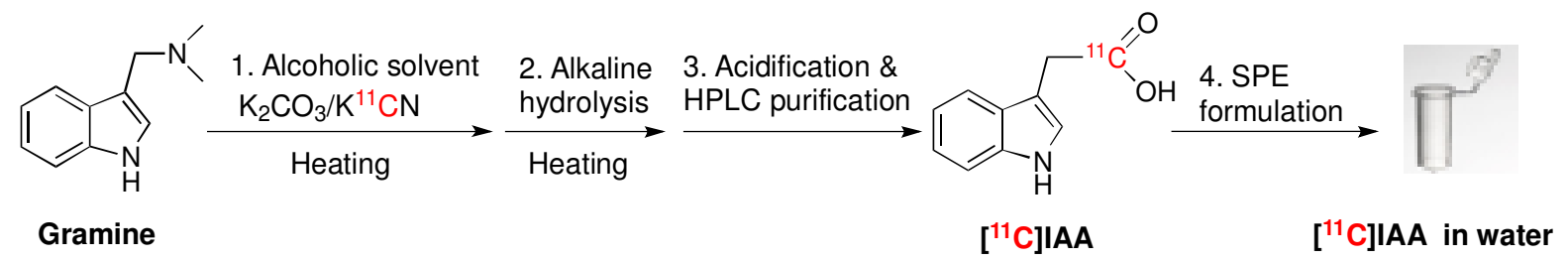

Scheme 2. Scheme of designed two-step-one-pot method

Hoping to improve the yield of the $\left.{ }^{[11} \mathrm{C}\right]$ cyanation reaction, ethanol was replaced with ethylene glycol (EG) and a higher reaction temperature $\left(145^{\circ} \mathrm{C}\right)$ was tested and the results showed that these changes clearly benefited the reaction (Entry 2). At this moment, another alcoholic solvent, tetraethylene glycol (TEG), was brought to our attention because it showed very good compatibility with nucleophilic substitution reactions. ${ }^{14}$ Presumably, this bis-terminal hydroxyl oligoether can act as a general $\mathrm{S}_{\mathrm{N}} 2$ reaction promoter by chelating with metallic cations and decreasing their interaction with the anion. Therefore, the nucleophilicity of an anion, such as cyanide ion, will be greatly enhanced. The next radiolabeling experiment, in which TEG and water were used as solvents, provided very promising results and the yield of $\left[{ }^{11} \mathrm{C}\right]$ cyanation reaction dramatically improved to 68\% (Entry 3). The overall yield of entire synthesis process, however, was still not adequate. An additional experiment showed that a shorter reaction time was better for the $\left[{ }^{11} \mathrm{C}\right]$ cyanation reaction (Entry 4$)$. The more meaningful result was that the overall yield sharply increased to $38 \%$ by increasing the base concentration (from $2 \mathrm{mmol}$ to $3 \mathrm{mmol}$ ) and water volume in the hydrolysis step. At this stage, we investigated the effect of temperature on the 
$\left.{ }^{[11} \mathrm{C}\right]$ cyanation reaction. The lower reaction temperature was less favored since it decreased the reaction yield (Entry 5). Increased temperature did not benefit the reaction, either (Entries 6 - 7). When water was removed entirely from the $\left.{ }^{[11} \mathrm{C}\right]$ cyanation reaction, the yield clearly dropped (Entry 8). When only a small portion of water $(0.02 \mathrm{~mL})$ added, the [11C]cyanation reaction yield increased to $81 \%$ (Entry 9). We speculate that the addition of water helped to dissolve the $\mathrm{K}_{2} \mathrm{CO}_{3}$ salt and that bringing potassium cation into the reaction system improved the solubility of $\left.{ }^{11} \mathrm{C}\right]$ cyanide anion in organic solvent. Presumably, increasing the amount of gramine precursor would improve the $\left[{ }^{11} \mathrm{C}\right]$ cyanation reaction yield. However, since we eliminated the purification of the $\left[{ }^{11} \mathrm{C}\right]$ IAN intermediate by SPE, the total mass of crude reaction mixture loaded onto the semiprep HPLC column when purifying the final product $\left[{ }^{11} \mathrm{C}\right] \mathrm{IAA}$ already exceeded that of our previous reported method.11,12 In order to assure adequate resolution for purification of the final product $\left.{ }^{[11} \mathrm{C}\right] \mathrm{IAA}$ and to extend the lifetime of the semi-prep HPLC column, we opted not to attempt to improve the yield by simply increasing the amount of starting material.

Table 1. Screen of better reaction conditions $\mathrm{s}^{\mathrm{a}, \mathrm{b}}$

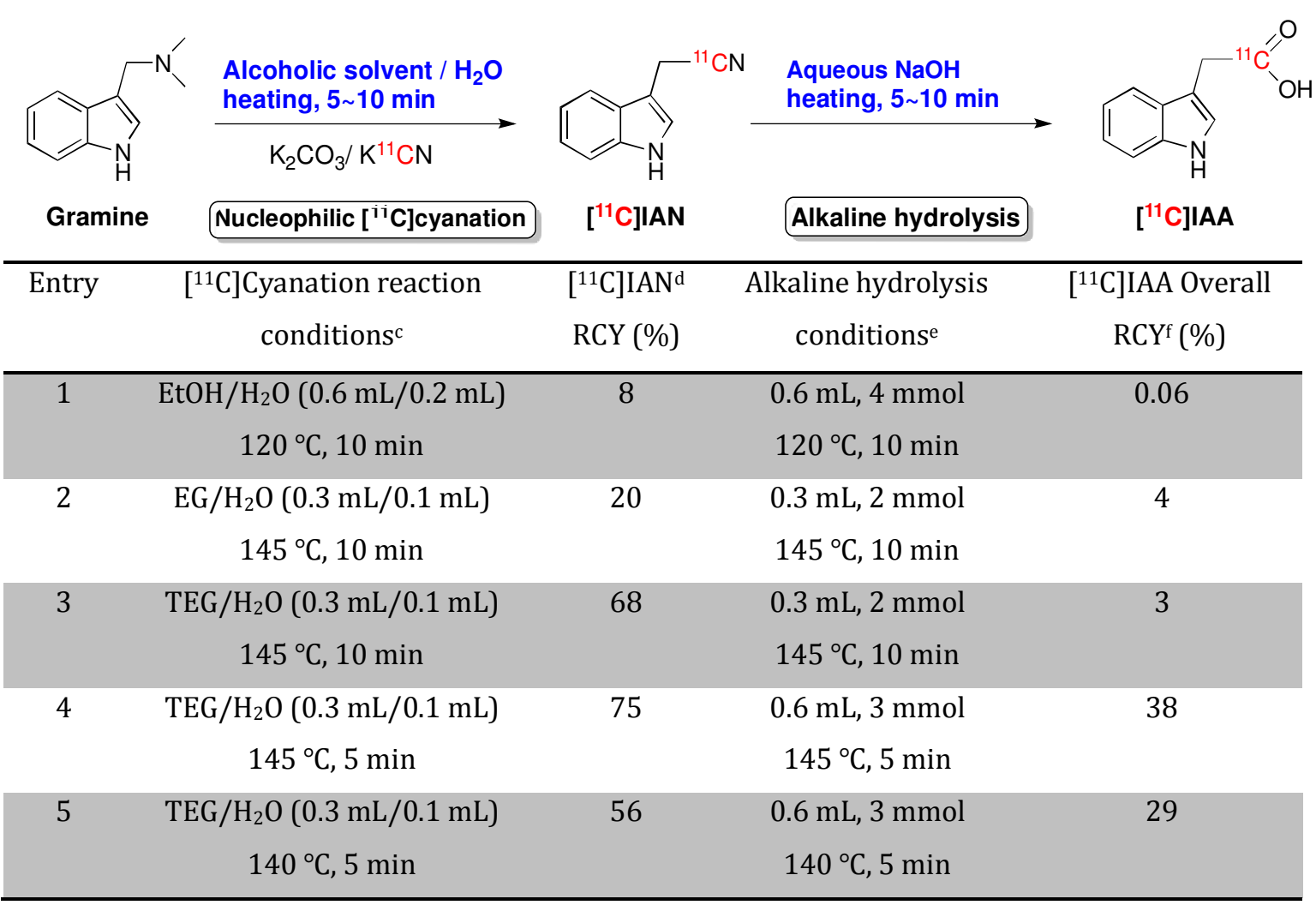




\begin{tabular}{|c|c|c|c|c|}
\hline \multirow[t]{2}{*}{6} & $\mathrm{TEG} / \mathrm{H}_{2} \mathrm{O}(0.3 \mathrm{~mL} / 0.1 \mathrm{~mL})$ & 73 & $0.6 \mathrm{~mL}, 3 \mathrm{mmol}$ & 37 \\
\hline & $150^{\circ} \mathrm{C}, 5 \mathrm{~min}$ & & $145^{\circ} \mathrm{C}, 8 \mathrm{~min}$ & \\
\hline \multirow[t]{2}{*}{7} & $\mathrm{TEG} / \mathrm{H}_{2} \mathrm{O}(0.3 \mathrm{~mL} / 0.1 \mathrm{~mL})$ & 75 & $\mathrm{~N} / \mathrm{A}$ & $\mathrm{N} / \mathrm{A}$ \\
\hline & $160^{\circ} \mathrm{C}, 5 \mathrm{~min}$ & & & \\
\hline \multirow[t]{2}{*}{8} & TEG $(0.3 \mathrm{~mL})$ & 62 & $0.75 \mathrm{~mL}, 3 \mathrm{mmol}$ & 33 \\
\hline & $145^{\circ} \mathrm{C}, 5 \mathrm{~min}$ & & $145^{\circ} \mathrm{C}, 8 \mathrm{~min}$ & \\
\hline \multirow[t]{2}{*}{9} & $\mathrm{TEG} / \mathrm{H}_{2} \mathrm{O}(0.3 \mathrm{~mL} / 0.02 \mathrm{~mL})$ & 81 & $0.75 \mathrm{~mL}, 3 \mathrm{mmol}$ & 25 \\
\hline & $145^{\circ} \mathrm{C}, 5 \mathrm{~min}$ & & $145^{\circ} \mathrm{C}, 8 \mathrm{~min}$ & \\
\hline
\end{tabular}

a A series of radiolabeling experiments was performed with a 2 min proton beam produced by a cyclotron. The ${ }^{14} \mathrm{~N}(\mathrm{p}, \alpha){ }^{11} \mathrm{C}$ nuclear reaction was induced by the proton irradiation to generate the radioisotope ${ }^{11} \mathrm{C}$ (refer to Supplementary data, General).

${ }^{b}$ Hydrogen $\left[{ }^{11} \mathrm{C}\right]$ cyanide was produced by our in-house built $\mathrm{H}^{11} \mathrm{CN}$ production system and trapped with $\mathrm{K}_{2} \mathrm{CO}_{3}$ in reaction vial efficiently as $\mathrm{K}^{11} \mathrm{CN}$ form. ${ }^{15}$

c Solvent, T ( $\left.{ }^{\circ} \mathrm{C}\right), \mathrm{t}(\mathrm{min}) ; \mathrm{EG}$ (ethylene glycol); TEG (tetraethylene glycol)

d RCY (radiochemical yield, decay-corrected) of [11C]IAN was calculated based on HPLC analysis of a measured aliquot of the crude reaction mixture.

e Total $\mathrm{H}_{2} \mathrm{O}(\mathrm{mL}), \mathrm{NaOH}(\mathrm{mmol})$; temperature $\left({ }^{\circ} \mathrm{C}\right)$, reaction time (min)

f Overall RCY of [11C]IAA was calculated based on HPLC analysis of measured aliquot of the crude product mixture for entry 1, 2, 3 and 6; hydrolysis step was not applicable for entry 7; overall RCY of [11C]IAA was obtained after semi-prep HPLC purification for entry 4, 5, 8 and 9.

At this stage, in addition to having optimized the $\left[{ }^{11} \mathrm{C}\right]$ cyanation reaction conditions (Table 1 , Entry 9), we had also gained important information about improving the alkaline hydrolysis reaction. There were two critical factors affecting hydrolysis of [11C]IAN. The first was that a sufficient amount of water was needed for hydrolysis, which is clear when comparing results of two experiments (Table 1, Entries 3 and 4). Secondly, in order to assure a rapid hydrolysis compatible with the short half-life of carbon-11 isotope, a high reaction temperature $\left(140-160{ }^{\circ} \mathrm{C}\right)$ is needed. During the experimental process (Table 1, Entry 3), we found that a small amount of water condensed at the top of the reaction vessel. We attributed the removal of $\mathrm{H}_{2} \mathrm{O}$ from the reaction mixture as the main cause of the low overall reaction yield (3\%). On one hand, it decreased the amount of $\mathrm{H}_{2} \mathrm{O}$ for the hydrolysis reaction; on the other hand, it clearly increased the concentration of $\mathrm{NaOH}$, which could possibly cause more side reactions. After increasing total water amount to $0.6 \mathrm{~mL}$, better reflux was observed and overall reaction yield was dramatically improved (Table 1, Entry 4). 
With the optimized $\left[{ }^{11} \mathrm{C}\right]$ cyanation reaction conditions in hand, we further scrutinized the alkaline hydrolysis conditions by fine-tuning several reaction parameters including the base strength, reaction time and reaction temperature (Table 2, Entries 10 to 15). The results showed that the combination of $0.75 \mathrm{~mL}$ of $\mathrm{H}_{2} \mathrm{O}, 4 \mathrm{M} \mathrm{NaOH}$ and 8 min reaction time increased the hydrolysis reaction yield to $55 \%$ (Table 2, Entry 15). In addition to $\mathrm{NaOH}, \mathrm{LiOH}$, which could be a mild basic hydrolysis agent, 16 was also tested for the alkaline hydrolysis reaction and only gave $31 \%$ yield and so is less favored for this reaction (Table 2, Entry 16).

Table 2. Further optimization of hydrolysis reaction of [11C]IAN to $\left.{ }^{11} \mathrm{C}\right] \mathrm{IAA}^{\mathrm{a}}$

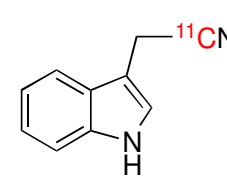

$\left[{ }^{11}\right.$ C]IAN
1. Aqueous base, $3.3-5.0 \mathrm{M}$ $140-145^{\circ} \mathrm{C}, 5-10 \mathrm{~min}$

2. $\mathrm{HCl}$ acidification

3. Semi-prep HPLC

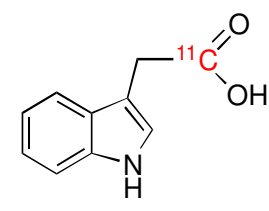

[11C]IAA

\begin{tabular}{|c|c|c|c|c|}
\hline Entry & Solvent ${ }^{\mathrm{b}}$ & $\begin{array}{c}\mathrm{NaOH} \\
\text { (mmol) }\end{array}$ & $\begin{array}{l}\text { Reaction time } \\
\text { (min) }\end{array}$ & $\begin{array}{c}\text { RCY }\left[{ }^{11} \mathrm{C}\right] \mathrm{IAA}^{\mathrm{c}} \\
(\%)\end{array}$ \\
\hline 10 & $\begin{array}{c}\text { TEG / } \mathrm{H}_{2} \mathrm{O}(0.3 \\
\mathrm{mL} / 0.6 \mathrm{~mL})\end{array}$ & 2 & 10 & 19 \\
\hline 11 & $\begin{array}{c}\text { TEG / } \mathrm{H}_{2} \mathrm{O}(0.3 \\
\mathrm{mL} / 0.6 \mathrm{~mL})\end{array}$ & 3 & 8 & 46 \\
\hline 12 & $\begin{array}{c}\text { TEG / } \mathrm{H}_{2} \mathrm{O}(0.3 \\
\mathrm{mL} / 0.6 \mathrm{~mL})\end{array}$ & 3 & 10 & 42 \\
\hline 13 & $\begin{array}{c}\text { TEG / } \mathrm{H}_{2} \mathrm{O}(0.3 \\
\mathrm{mL} / 0.6 \mathrm{~mL})\end{array}$ & 3 & 5 & 35 \\
\hline $14^{d}$ & $\begin{array}{c}\text { TEG / } \mathrm{H}_{2} \mathrm{O}(0.3 \\
\mathrm{mL} / 0.6 \mathrm{~mL})\end{array}$ & 3 & 8 & 34 \\
\hline 15 & $\begin{array}{c}\text { TEG / } \mathrm{H}_{2} \mathrm{O}(0.3 \\
\mathrm{mL} / 0.75 \mathrm{~mL})\end{array}$ & 3 & 8 & 55 \\
\hline 16 & $\begin{array}{c}\text { TEG / } \mathrm{H}_{2} \mathrm{O}(0.3 \\
\mathrm{mL} / 0.75 \mathrm{~mL})\end{array}$ & $3(\mathrm{LiOH})$ & 8 & 31 \\
\hline
\end{tabular}

a Hydrolysis and $\left[{ }^{11} \mathrm{C}\right]$ cyanation were carried out in the same reaction vessel without intermediate purification.

b The solvents for hydrolysis came from the $\left[{ }^{11} \mathrm{C}\right]$ cyanation reaction and extra water and $\mathrm{NaOH}$ were added.

c [ $\left.{ }^{11} \mathrm{C}\right]$ IAA was purified by semi-prep HPLC and RCY (decay-corrected) in this table refers to conversion in the hydrolysis step only $\left(100 \times\left[{ }^{11} \mathrm{C}\right] \mathrm{IAA} /\left[{ }^{11} \mathrm{C}\right] \mathrm{IAN}\right)$.

d All the experiments above were performed at $145^{\circ} \mathrm{C}$ except for entry 14 which was conducted at $140^{\circ} \mathrm{C}$. 
Once conditions for both the $\left[{ }^{11} \mathrm{C}\right]$ cyanation and hydrolysis steps were optimized, a new two-step, one-pot method was established for rapidly synthesizing the PET radiotracer [11C]IAA. By replacing the polar aprotic solvent DMSO with tetraethylene glycol, the SPE purification of reaction intermediate $\left[{ }^{11} \mathrm{C}\right] \mathrm{IAN}$ was successfully eliminated from the whole synthesis process. Both the nucleophilic $\left[{ }^{11} \mathrm{C}\right]$ cyanation and alkaline hydrolysis reactions can be consecutively performed in one pot. This change obviously simplified the synthesis process and shortened the total synthesis time from $80-85 \mathrm{~min}$ to $55-60 \mathrm{~min}$. In addition, the investigation of several reaction parameters for both reactions, such as reaction temperature, reaction time, solvent amount and base strength, etc., helped to further polish the whole synthetic process. To confirm the robustness of our newly developed synthetic method, we combined the optimum reaction conditions for both reactions (Table 1, Entry 8 and Table 2, Entry 15) and repeated the synthesis of [11C]IAA five times under the optimized reaction conditions (Scheme 3). The results show the high reliability of this newly established synthetic process. With a two-min cyclotron beam time, which generates $\sim 8.1 \mathrm{GBq}$ $(220 \mathrm{mCi})$ of ${ }^{11} \mathrm{CO}_{2}, 0.22-0.46 \mathrm{GBq}(6.1-12.4 \mathrm{mCi})$ of [11C]IAA product was obtained at the end of synthesis (EOS). The overall yield (RCY) for both steps was $33 \pm 9.5 \%$ (calculated from $\mathrm{H}^{11} \mathrm{CN}$ radioactivity collected in reaction vessel) and was $18.9 \pm 6.4 \%$ (calculated from ${ }^{11} \mathrm{CO}_{2}$ radioactivity generated from a two-min cyclotron beam). The radiochemical purity of final product was $98 \%$ and the specific activity of final product was $47.4 \pm 12.5 \mathrm{GBq} / \mu \mathrm{mol}$. The complete processing time, calculated from end of bombardment (EOB) to the end of formulation, ranged from 55 to 60 min.

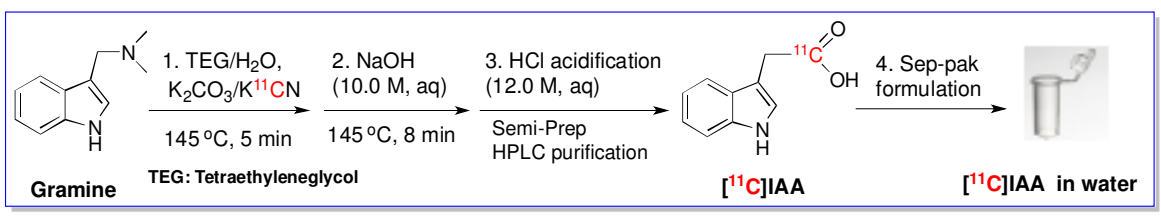

Scheme 3. Reaction parameters of the optimized two-step, one-pot method

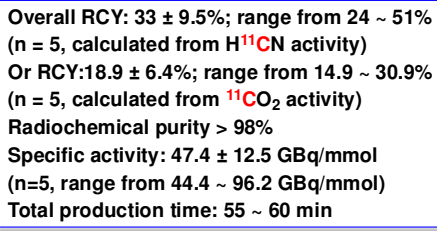
Total production time: $55 \sim 60 \mathrm{~min}$

\section{Conclusion}


In summary, we successfully developed a two-step, one-pot method for routine production of [11C]IAA to support plant imaging research. By replacing the polar aprotic solvent DMSO with protic tetraethylene glycol, both $\left[{ }^{11} \mathrm{C}\right]$ cyanation and alkaline hydrolysis reactions were performed in same pot without purification of the [11C]IAN intermediate and whole process successfully yielded [11C]IAA with high radiochemical purity and high specific activity with reasonable radiochemical yield. The total synthesis time required is $40 \mathrm{~min}$ and the entire production cycle including HPLC purification and formulation product into a small volume of aqueous solution $(0.15-0.3 \mathrm{~mL})$ was complete in $55 \mathrm{~min}$. Considering the short half-life of carbon-11 (20.4 min), reducing the total production time to less than $60 \mathrm{~min}$ and simplifying the synthesis procedure is exceedingly beneficial to the practical use of this tracer for in vivo PET imaging studies. Furthermore, the efficient $\left[{ }^{11} \mathrm{C}\right]$ cyanation procedure specifically using tetraethylene glycol with potassium salts as a nucleophilic substitution promoter is potentially useful for the development of other $\left[{ }^{11} \mathrm{C}\right]$ cyanation reactions when preparing PET radiotracers containing the $\left[{ }^{11} \mathrm{C}\right]$ cyano group. Research utilizing the radiotracer $\left[{ }^{11} \mathrm{C}\right] \mathrm{IAA}$ for in vivo plant studies via PET imaging is in progress.

\section{Acknowledgements}

This manuscript has been co-authored by employees of Brookhaven Science Associates, LLC under

Contract DE-AC02-98CH10886 with the U. S. Department of Energy, Office of Biological and Environmental Research within the Office of Science. We thank David Schlyer and Richard Ferrieri for advice and encouragement.

\section{Supplementary data}

Supplementary data associating this article can be found, in the online version at 


\section{References and notes}

(1) Ludwig-Muller, J. Plant Growth Regulation 2000, 32, 219.

(2) Thimann, K. V.; Koepfli, J. B. Nature (London, United Kingdom) 1935, 135, 101.

(3) Pollmann, S.; Duechting, P.; Weiler, E. W. Phytochemistry (Elsevier) 2009, 70, 523.

(4) Robert, C. A. M.; Ferrieri, R. A.; Schirmer, S.; Babst, B. A.; Schueller, M. J.; Machado, R. A. R.; Arce, C. C. M.; Hibbard, B. E.; Gershenzon, J.; Turlings, T. C. J.; Erb, M. Plant, Cell and Environment 2014, 37, 2613.

(5) Hanik, N.; Gomez, S.; Schueller, M.; Orians, C. M.; Ferrieri, R. A. Plant, Cell and Environment 2010, 33, 2173.

(6) Gomez, S.; Ferrieri, R. A.; Schueller, M.; Orians, C. M. New Phytologist 2010, 188, 835.

(7) Thorpe, M. R.; Ferrieri, A. P.; Herth, M. M.; Ferrieri, R. A. Planta 2007, 226, 541.

(8) Ferrieri, R. A.; Gray, D. W.; Babst, B. A.; Schueller, M. J.; Schlyer, D. J.; Thorpe, M. R.; Orians, C. M.; Lerdau, M. Plant, Cell and Environment 2005, 28, 591.

379.

(9) Herth, M. M.; Thorpe, M. R.; Ferrieri, R. A. J. Labelled Compd. Radiopharm. 2005, 48, $53,592$.

(10) Kasel, M. C. K.; Schueller, M. J.; Ferrieri, R. A. J. Labelled Compd. Radiopharm. 2010,

(11) Reid, A. E.; Kim, S. W.; Seiner, B.; Fowler, F. W.; Hooker, J.; Ferrieri, R.; Babst, B.; Fowler, J. S. J. Labelled Compd. Radiopharm. 2011, 54, 433.

(12) Xu, Y.; Alexoff, D. L.; Kunert, A. T.; Qu, W.; Kim, D.; Paven, M.; Babst, B. A.; Ferrieri, R. A.; Schueller, M. J.; Fowler, J. S. Appl. Radiat. Isot. 2014, 91, 155.

(13) Snyder, H. R.; Pilgrim, F. J. J. Am. Chem. Soc. 1948, 70, 3770.

(14) Lee, J. W.; Yan, H.; Jang, H. B.; Kim, H. K.; Park, S.-W.; Lee, S.; Chi, D. Y.; Song, C. E. Angew. Chem. Int. Ed. 2009, 48, 7683.

(15) Kim, D.; Alexoff, D.; Kim, S. W.; Hooker, J.; Ferrieri, R. A. U.S. Pat. Appl. Publ. (2013), US 20130045151 A1 20130221.

(16) Dayal, B.; Salen, G.; Toome, B.; Tint, G. S.; Shefer, S.; Padia, J. Steroids 1990, 55, 233. 


\title{
Tetraethylene glycol promoted two-step, one-pot rapid synthesis of indole-3-[1-11 C]acetic Acid
}

So Jeong Leea, b, David L. Alexoffa, Colleen Sheaa, Dohyun Kima, Michael Schuellera, Joanna S. Fowlera,

\author{
Wenchao Qua, *
}

aBiological, Environmental \& Climate Sciences Department, Brookhaven National Laboratory,

Upton, NY 11973, USA

bDepartment of Chemistry, Stony Brook University, Stony Brook, NY 11794, USA

Email: wqu@bnl.gov

\section{Graphic abstract}

\section{Previously reported $\left[{ }^{11} \mathrm{C}\right]$ IAA production method}

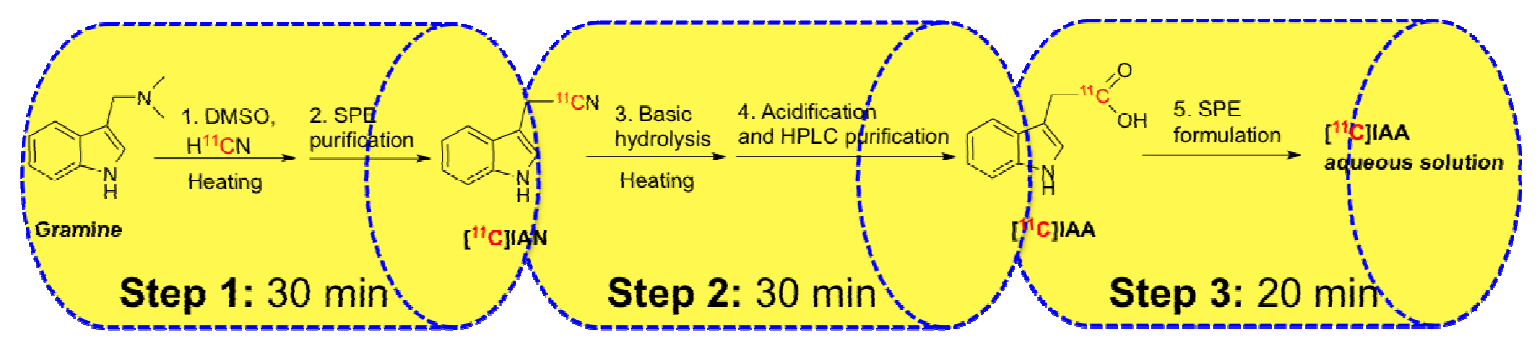

New two-step, one-pot method

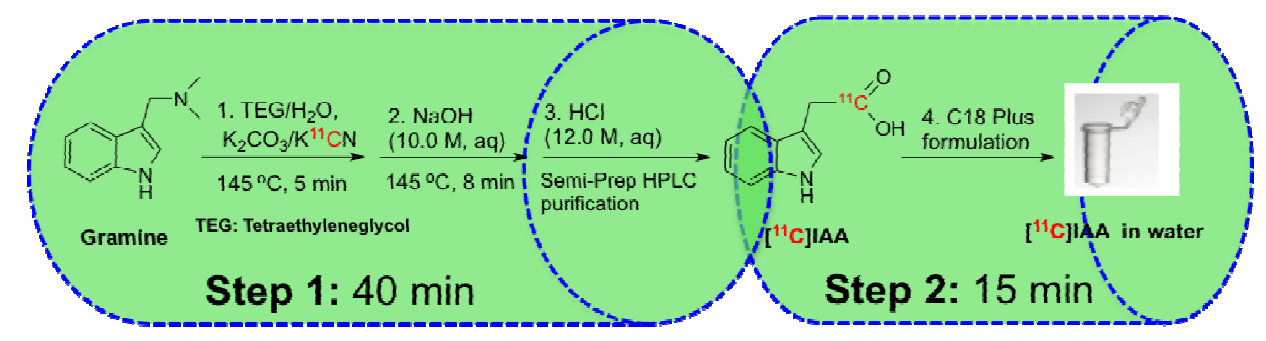

